\title{
Memories of Shame Experiences with Others and Depression Symptoms: The Mediating Role of Experiential Avoidance
}

\author{
Sérgio Carvalho, ${ }^{*}$ Alexandra Dinis, José Pinto-Gouveia and Cátia Estanqueiro
}

Cognitive-Behavioral Research Centre, University of Coimbra, Coimbra, Portugal

\author{
*Correspondence to: Sérgio Carvalho, CINEICC, Faculty of Psychology \\ and Education Sciences, University of Coimbra, Rua do Colégio \\ Novo, Apartado 6153, 3001-802 Coimbra, Portugal. \\ E-mail: sergio.and.carvalho@gmail.com
}




\begin{abstract}
Background: Shame experiences have been suggested to be related with psychopathological symptoms and with self-relevant beliefs. Recent studies also suggest that avoidant-focused strategies (e.g., rumination, thought suppression and dissociation) mediate the impact of shame memories and depression symptoms. However, experiential avoidance has been found to mediate the relation between early experience of abuse and psychopathological symptoms. Our goal was to test the mediating effect of experiential avoidance in the relation between both the nature of shame experiences at the hands of caregivers and the centrality of shame memories with others, and depression symptoms.
\end{abstract}

Method: Using structural equation modelling, we assessed the frequency and nature of recalled shame experiences at the hands of caregivers, the centrality of shame experiences with others throughout childhood and adolescence, experiential avoidance and depression symptomatology in 161 participants from general population.

Results: Experiential avoidance mediates the impact of shame experiences with caregivers and depression symptoms. Experiential avoidance also mediated the association between the centrality of shame experiences with others and depression symptoms.

Conclusion: Our results suggest that shame memories with others do not per se impact on depression symptoms, but rather the unwillingness to experience them and the attempts to control them. Hence, our results emphasize the importance of addressing affect regulation processes such as avoidance when dealing with shame memories, particularly with patients who experience depression symptoms.

Keywords: Recall of Shame Experiences, Centrality of Shame Memories, Experiential Avoidance, Depression Symptoms.

\title{
Key Practitioner Message:
}

- The recall of shame experiences with caregivers is associated with the experience of depression symptoms, even when these experiences are not perceived as central points to one's life identity and story. This seems to suggest a necessity to explore these experiences in a therapeutic setting.

- Our findings suggest that experiential avoidance is a key process through which these 
memories of shame experiences impact on depression symptomatology. Hence, it seems to be of great importance to reduce experiential avoidance and help people change the way they relate with these memories.

\section{INTRODUCTION}

\section{Shame}

Shame is a self-conscious emotion (Gilbert, 2002) with a great evolutionary relevance. It is rooted in a social threat system in which the self is perceived as an object of negative evaluation by others, anticipating their rejection or even attack (Gilbert, 2000, 2002). Given that humans compete for the approval, acceptance and investment of others (Gilbert, 2003), shame acts as an inner warning signal of social threat, triggering a set of submissive and appeasement behaviours (e.g., keep head down, avoid eye gaze, hide and escape) that aimto deescalate and/or avoid interpersonal conflict that could lead to social rejection or devaluation (Gilbert \& McGuire, 1998; Gilbert, 2002). Although shame is an adaptive emotion and essential to normal development, it has been agreed that, when it becomes a dominant emotion, it can lead to maladaptive and pervasive outcomes (Gilbert, 1998; Kaufman, 1989; Lewis, 1992; Mills, 2005; Schore, 1998). Indeed, although feeling shame is an innate capacity (Gilbert \& McGuire, 1998), there has been a great number of studies showing an association between shame and psychopathological symptoms (Averill, Diefenbach, Stanley, Breckenridge, \& Lusby, 2002; Gilbert, Allan, \& Goss, 1996; Tangney \& Dearing, 2002), particularly with eating disorders (Goss \& Allan, 2009; Keith, Gillanders, \& Simpson, 2009), social anxiety (Grabhorn, Stenner, Stangier, \& Kaufhold, 2006), depression (Andrews, Quian, \& Valentine, 2002; Cheung, Gilbert, \& Irons, 2004; Gilbert, 2000; Tangney, Wagner, \& Gramzow, 1992) and post-traumatic stress disorder (PTSD) symptoms (Andrews, Brewin, Rose, \& Kirk, 2000; Robinaugh \& McNally, 2010; Wekerle et al., 2009). Because the experience of shame is accompanied with the perception that one has personal attributes or actions that are unattractive, worthless and powerless (Lewis, 1992; Tangney et al., 1992), it has been proposed that shame-rearing experiences play a significant role in our self-identity and sense of self (Gilbert, 1998; Kim, Thibodeau, \& Jorgensen, 2011; Lewis, 1992).

\section{Shame memories as autobiographical memories}

Autobiographical memory has been described as the recollection of one's personal experiences that incorporates aspects of verbal description and mental imagery and is often accompanied with emotional experiencing and a sense of reliving (Greenberg \& Rubin, 2003). The set of autobiographical memories is combined through a reasoning process into a coherent life story related to the current self (Habermas \& Bluck, 2000) and is usually recorded as a narrative told to others and to oneself (Greenberg \& Rubin, 2003). The aspects of the personal experience that are better encoded and consolidated in autobiographical memory have motivated a great number of studies (see Holland \& Kensinger, 2010, for a review) that suggest that the emotional intensity of the memory is the best predictor of the frequency of recalling past events (Berntsen $\&$ Rubin, 2008; Rubin \& Berntsen, 2009; Talarico, LaBar, \& Rubin, 2004), with these memories being more vivid, more likely to be accompanied by intense negative emotions (Wenzel, Pinna, \& Rubin, 2004), more coherent (Porter \& Peace, 2007) and more rehearsed and central to ones' life story (Rubin, Dennis, \& Beckham, 2011) when they are trauma-related memories (Thomsen \& Berntsen, 2009). Early shaming 
experiences can be an emotionally charged part of autobiographical memories (Gilbert, 2002; Gilbert \& Irons, 2005; Gilbert \& Procter, 2006; Lewis, 1992). Excessive proneness to feel shame has been pointed out as a result of negative self-representations that are internalized through early negative rearing experiences with caregivers (Claesson \& Sohlberg, 2002; Gilbert \& Gerlsma, 1999; Kaufman, 1989). Shame experiences are characterized as situations in which one is criticized, rejected, excluded or ignored by others, resulting in an internalized sense of self as unattractive, undesirable, defective and unlovable (Gilbert, 1998, 2003). For example, the use of expressions such as 'I thought you were better than that', 'if you keep getting fat no one will love you' or 'you're a disappointment' by a parent or the rejection by a lover would constitute a shame experience (Matos, Pinto-Gouveia, \& Costa, 2011). Indeed, the influence of the rearing environment and parent-child relationship in a child's socio-emotional development (Eisenberg, Cumberland, \& Spinrad, 1998; Eisenberg et al., 2001, 2003; Valiente, Fabes, Eisenberg, \& Spinrad, 2004), formation of self-relevant beliefs (Gilbert et al., 1996; Gilbert, 1998, 2002, 2005) and formation of emotional self-regulation skills (Gottman, Katz, \& Hooven, 1997; Thompson \& Goodman, 2010) has been strongly established in literature. Although shame has an essential developmental role in promoting socially acceptable behaviour (Mills, Arbeau, Lall, \& De Jaeger, 2010), it has been pointed out that persistent, criticism, shaming and put-down experiences with caregivers might lead to an internalization of the self as flawed, inferior, rejectable (Castilho, Pinto-Gouveia, Amaral, \& Duarte, 2012; Gilbert, 2002; Mikulincer \& Shaver, 2005), inadequate and worthless (Claesson \& Sohlberg, 2002; Gilbert et al., 1996; Gilbert \& Gerlsma, 1999). In fact, studies have shown that when there is an absence of warmth and safeness and/or when threatening, shaming and put-down experiences are part of a child's daily life, it can lead to an understimulation of positive affect and warmth systems (Irons, Gilbert, Baldwin, Baccus, \& Palmer, 2006) and/or an overstimulation of the threat system (Gilbert, 2005), which might result in fear-based submissive behaviour (Gilbert, Cheung, Grandfield, Campey, \& Irons, 2003) and lead to psychopathology (Gilbert, 2005). Since early shaming events are remembered as emotionally intense experiences and since emotional intensity has been suggested as a significant part of autobiographical memories (Berntsen \& Rubin, 2008; Rubin \& Berntsen, 2009; Talarico et al., 2004), it has been recently proposed and shown that early shame experiences might not only have trauma-like characteristics (Matos \& Pinto-Gouveia, 2009; Matos et al., 2011) but also be integrated as a central part of emotionally charged autobiographical memory (Pinto-Gouveia \& Matos, 2010).

\section{Shame Memories and the Centrality of Event Theory}

Although it has been suggested that positive life experiences are generally judged as more central to life story and identity (Berntsen, Rubin, \& Siegler, 2011), it has been shown that negative events can be considered more central to one's life story when they enclose trauma-like characteristics (e.g., memory intrusion, avoidance and hyperarousal symptoms) (Berntsen \& Rubin, 2006, 2007; Rubin et al., 2011). Indeed, there has been an increasing number of studies suggesting that participants with PTSD symptoms report more memories related to the trauma than those without PTSD symptoms (Berntsen \& Rubin, 2008; Sutherland \& Bryant, 2008) and that these traumatic memories are not only more consistent over time than positive memories but also more vivid (Berntsen, Willert, \& Rubin, 2003) and with more sensory componentes (Porter \& Peace, 2007). Berntsen and Rubin $(2006,2007)$ proposed that, regardless of its severity, a traumatic experience is encoded as an emotional autobiographical memory that can lead to problematic outcomes due to three intertwined and overlapping functions. These negative emotional memories may function as reference points for everyday inferences, representing an anchor to daily inferences, giving meaning to later experiences unrelated to the 
trauma and creating expectations regarding the future. This implies, for instance, that one may worry or anticipate a negative outcome such as a future trauma (Berntsen \& Rubin, 2007), which may lead to avoidance of experiences that one perceives as potentially harmful or unpleasant. They can also represent turning points in life stories, i.e., episodes that may alter or redirect life course and serve as an explanation for later personal choices, behaviours and values (Matos, Pinto-Gouveia, \& Gomes, 2010) and its content spontaneously evoked as a response to internal or external stimuli (Berntsen \& Rubin, 2006). As a consequence, it can not only build a personal life story where the positive nontraumatic events prior to the shameful experience are nulled, reinterpreted and/or associated with its negative emotions but also lead to biased processing of current life events (Matos et al., 2010). These experiences may also be crucial components of personal identity, since these autobiographical memories can be related with how we understand ourselves (Berntsen \& Rubin, 2006). Since memories of shame experiences can be loaded with intense emotional texture and assume a traumatic nature (Matos \& Pinto-Gouveia, 2009; Matos et al., 2011) and since a traumatic event can become central to a person's life story and identity (Berntsen \& Rubin, 2007), memories of early shame experiences were proposed and shown to be recorded as autobiographical memories, functioning as central reference points to our identity and life story (Pinto-Gouveia \&Matos, 2010). In fact, these experiences characterized by criticism, rejection and putdown are overall threat autobiographical memories and are believed to be internalized as self-beliefs (Berntsen \& Rubin, 2006; Gilbert, 1998; Gilbert \& Procter, 2006; Tangney \& Dearing, 2002), hence central to one's narrative about the self.

\section{Adverse Rearing Experiences, Experiential Avoidance and Psychopathology}

It is widely accepted that negative rearing experiences with caregivers, such as shaming and put-down experiences, play an important role on later psychopathology (e.g., Gilbert, 1998; Kaufman, 1989; Lewis, 1992; Mills, 2005; Schore, 1998), and that these negative experiences are associated with the development of emotional self-regulatory skills (Gottman et al., 1997; Thompson \& Goodman, 2010), although the processes through which these experiences impact later in life are not entirely clear. Experiential avoidance has recently been shown to be a relevant psychological process in understanding psychopathological symptoms. According to the acceptance and commitment therapy (ACT; Hayes, Strosahl, \& Wilson, 1999), experiential avoidance is one of the processes that contribute to psychological inflexibility, and it is characterized as the unwillingness to be in contact with one's private experiences (e.g., bodily sensations, thoughts, emotions and behaviour consequences) (Blackledge \& Hayes, 2001; Hayes, 2004; Wilson \& Murrell, 2003), leading to the attempt of deliberately controlling the form, frequency and context in which they occur (Hayes, 1994; Hayes et al., 1999; Hayes, Wilson, Gifford, Follette, \& Strosahl, 1996). Although it is not per se a pervasive process, experiential avoidance turns into a disordered process when it serves the purpose of rigidly and inflexibly controlling undesired internal events (Kashdan, Barrios, Forsyth, \& Steger, 2006), pushing one away from valued life goals (Hayes et al., 1999). In fact, there are a substantial number of studies showing an association between experiential avoidance and cognitive suppression (Campbell-Sills, Barlow, Brown, \& Hofmann, 2006; Gross, 1998; Feldner, Zvolensky, Eifert, \& Spira, 2003), rumination (Cribb, Moulds, \& Carter, 2006; NolenHoeksema \& Harrel, 2002), coping strategies and psychopathology in chronic pain (Costa \& PintoGouveia, 2011) and maladaptive perfectionism and worry (Santanello \& Gardner, 2007) and showing experiential avoidance as a contributor in borderline personality disorder symptom severity (Iverson, Follette, Pistorello, \& Fruzzetti, 2011). The role of experiential avoidance in the relation between early experiences and several later outcomes has also been recently studied. Research has suggested that individuals with a childhood 
abuse history presente heightened experiential avoidance (Batten, Follette, \& Aban, 2001; Gratz, Bornovalova, Delany-Brumsey, Nick, \& Lejuez, 2007) and tend to use avoidant coping strategies such as thought suppression (Krause, Mendelson, \& Lynch, 2003). In addition, the role of experiential avoidance in developing and maintaining various PTSD symptoms has been recently suggested (Kumpula, Orcutt, Bardeen, \& Varkovitzky, 2011), and there has been a greatdeal of results pointing to the mediating role of experiential avoidance, such as between abuse and later depression and PTSD symptoms (Merwin, Rosenthal, \& Coffey, 2009), between adverse childhood experiences and obsessive-compulsive symptoms (Briggs \& Price, 2009) and between traumatic events and PTSD symptoms (Orcutt, Pickett, \& Pope, 2005). More recently, results have also suggested a mediating role of experiential avoidance strategies such as rumination, thought suppression and dissociation between traumatic shaming experiences with others and depressive symptoms (Matos et al., 2011). Although it has been suggested that shaming experiences have an impact on psychopathological symptoms (Gilbert, 1998; Kaufman, 1989; Lewis, 1992; Mills, 2005; Schore, 1998), this has not been, to our knowledge, studied using any instrument specifically developed to assess the nature and frequency of memories of shame, criticismo and put-down by caregivers (as the Shame Experiences Scale was designed to do). In addition, although it has recently been demonstrated that shame experiences that turned out to be central to one's life story and identity predict depression symptoms (Pinto-Gouveia \&Matos, 2010), the processes through which it occurs have not been studied. Finally, although adverse and abusive childhood experiences have been increasingly suggested to be related with the use of emotion regulatory avoidant strategies (Batten et al., 2001; Gratz et al., 2007), we did not find any study relating shame memories, experiential avoidance and depression. In fact, we are only aware of one study that demonstrates that several avoidant strategies (e.g., rumination, thought suppression and dissociation) mediate the impact of shame memories and depression symptoms (Matos et al., 2011).

\section{THE CURRENT STUDY}

This research sets out to study the relation between the centrality of shame experiences and later experiential avoidance and depression symptoms.We expect that participants who state their shame experiences throughout childhood and adolescence as being central to their life story and identity and serve as reference points for everyday inferences are more likely to be unwilling to experience their private transient events (e.g., thoughts, emotions and bodily sensations) and deliberately try to control them (experiential avoidance) and aremore likely to have depression symptoms. In addition, this study aims to contribute to the clarification of the impact of the nature itself of shame experiences with caregivers on later development of experiential avoidance and depressive symptoms. We propose that individuals that recall shaming, criticism and put-down experiences with caregivers in childhood and adolescence are more likely to be experientially avoidant and are more likely to experience depression symptoms. Finally and in line with literature review and research regarding the mediator effect of experiential avoidance in the relation between early abusive experiences and later psychopathological symptoms (e.g., Briggs \& Price, 2009; Merwin et al., 2009; Orcutt et al., 2005), we propose that experiential avoidance acts as a mediator between the recall of shame experiences, regardless of their centrality, and depression symptoms.

\section{METHOD}

\section{Participants}

A total of 161 Caucasian and Portuguese subjects of general population completed several self-report 
measures. In this sample, $42.9 \%$ are male $(n=69)$, with a mean age of $34.03(\mathrm{SD}=9.65)$ years, and $57.1 \%$ were female $(n=92)$, with a mean age of $34.78(\mathrm{SD}=10.10)$ years. On average, participants had 14.96 years of education ( $\mathrm{SD}=3.23)$. Concerning marital status, $42.4 \%$ were married or in a relationship $(\mathrm{n}=68), 6.8 \%$ were divorced $(n=11), 50.3 \%$ were single $(n=81)$ and $0.6 \%$ were widows $(n=1)$. Participant mean scores did not meet cut-offs for clinical depression. It is also worth mentioning that the mean scores of shame experiences with caregivers (assessed with the Shame Experiences Scale) were similar to the ones obtained by the authors of the scale (i.e., our study: $\mathrm{M}=1.70, \mathrm{DP}=0.59$; original study of the scale: $\mathrm{M}=1.73, \mathrm{DP}=0.62$ ) (Dinis, Matos, Pinto-Gouveia, \& Magalhães, ). The exclusion criteria included (a) age of less than 18 years and more than 65 years; (b) subjects that come from the student population; (c) subjects who reported difficulties that compromised the reading or understanding of questionnaire items; (d) incompletely filled scales/missing index higher than $10 \%$ in each scale; and (e) clear evidence of compliance of the instructions on responses.

\section{Procedure}

The underlying protocol to our research contains four selfreport measures that aimed to assess the nature and frequency of shame experiences at the hands of caregivers, the centrality of shame experiences with others, experiential avoidance and depression symptoms. This protocol also contained a participant's information sheet, which included a brief explanation and the aims of the study, as well as a collection of demographic data. A convenience sample was collected within the staff of public institutions (e.g., schools) and private corporations. The protocols were administered by the authors Sérgio Carvalho and Cátia Estanqueiro to volunteers of the general nonstudent population. The confidentiality of answers was also ensured and it was guaranteed that the information granted would only be used for the purpose of the study. Moreover, it was emphasized that participants' collaboration was voluntary, and participants' informed consents were provided.

\section{Measures}

The 42-item Depression, Anxiety and Stress Scale (Lovibond \& Lovibond, 1995; translation and adaptation: Pais-Ribeiro, Honrado, \& Leal, 2004) self-report questionnaire was designed to measure three dimensions of psychopathological symptoms: depression, anxiety and stress. The items indicate negative emotional symptoms of which the respondents rated on a 4-point scale (0-3). For the purpose of our study, we only used the depression subscale. Total scores are calculated by summing the items on each scale, and the higher the score, the more a subject experiences depression symptoms. In the original version, Lovibond and Lovibond (1995) found the subscales to have high internal consistency (depression subscale Cronbach's $\alpha=0.91$; anxiety subscale Cronbach's $\alpha=0.84$; stress subscale Cronbach's $\alpha=0.90$ ). The Portuguese adaptation has a Cronbach's alpha ranging from 0.83 to 0.93 (Pais-Ribeiro et al., 2004). In the present study, we obtained a Cronbach's $\alpha=0.93$ for the depression subscale.

The Acceptance and Action Questionnaire II (Bond et al., 2011; translation and adaptation: Pinto-Gouveia, Gregório, Dinis, \& Xavier, 2012) is a seven-item self-report measure of psychological inflexibility, which has been used to measure experiential avoidance. This instrument assesses tendencies to make negative evaluations of private events and the unwillingness to be in contact with private events (e.g., 'I'm afraid of my feelings' and 'my painful memories prevent me from having a fulfilling life'). Respondents analyse how each statement applies to them, using a 7-point Likert response format type (1, never true; 7, always true), and the total score is attained by summing the items, with higher results indicating higher levels of experiential avoidance. The 
original version has good psychometric qualities, including an internal consistency of $\alpha=0.84$ (Bond et al., 2011). The Portuguese version had an internal consistency of $\alpha=0.89$ (Pinto-Gouveia et al., 2012). In this study, we achieved an internal consistency of $\alpha=0.90$.

The Shame Experiences Scale (Dinis et al., ) consists of 15 questions to assess the experiences of shame in childhood and adolescence, i.e., the extent to which respondentes felt humiliated, criticized, degraded and shamed by their parents, and how frequent those shame experiences occurred. More specifically, the items refer to retrospective memory, and the participants are asked to assess the degree of agreement with regard to father and mother separately, based on the frequency with which each of the situations exemplified happened to him (ranging from $1=$ 'never true' to $5=$ 'always true'). The higher the score of the items (e.g., 'When I used to do something wrong, my father/mother often reminded me of that', 'my father/mother made me feel that I embarrassed them in public' and 'my father/mother used to compare my performance with other children's performance, making me feel weak and inferior'), the more frequente was that shame experience. The authors of the scale found a consistency of 0.93 for the father subscale and 0.92 for the mother subscale. Exploratory factor analyses supported a single-factor structure for father and mother versions. Also, confirmatory factor analyses on both versions of the scale confirmed the fit of the 15-item model. Convergent and divergent validity of the scale was analysed in relation to other instruments widely known in literature and research, such as The Early Life Experiences Scale (Gilbert et al., 2003), The Childhood Experience of Care and Abuse Questionnaire (Smith, Lam, Bifulco, \& Checkley, 2002), Parental Bonding Instrument (Parker, Tupling, \& Brown, 1979), Family Expressivity Questionnaire (Halberstadt, 1986), Types of Positive Affect Scale (Gilbert et al., 2008) and the 42-item Depression Anxiety Stress Scales (Lovibond \& Lovibond, 1995). Given the high correlation between the two subscales for parents $(r=0.69)$ and since our aim was not to investigate the separate influence of shame experiences with fathers and mothers, but rather to explore these experiences with parents as a global variable, we have chosen to consider a variable combination of parental experiences of shame. The internal consistency analysis yielded a Cronbach's alpha of 0.95 for the total score on the parents.

The Centrality of Event Scale (Berntsen \& Rubin, 2006; translated and adapted byMatos et al., 2010) measures the extent to which a memory of a stressful event forms a reference point for personal identity and for the attribution of meaning to ulterior personal life experiences. This 20 -item self-report questionnaire, rated on 5-point scales ( 1 = totally disagree; 5=totally agree), assesses the three interdependent characteristics of highly negative emotional memories: reference points for everyday inferences ('This event has coloured the way I think and feel about other's experiences'), turning points in life stories ('I feel that this event has become a central part of my life story') and components of personal identity ('I feel that this event has become part of my identity'). In our study, in order to be in consonance with its aims, we modified the instructions to prime participants to remember a shame experience with others in childhood or adolescence. This modification has already been performed in another study (Pinto-Gouveia \& Matos, 2010), and the validation of the instrument did not seem to be affected. In its original study, the Centrality of Event Scale reported a high internal consistency $(\alpha=0.95)$, and in the Portuguese version, the authors also found a high internal consistency $(\alpha=$ 0.96). In our study, we achieved an internal consistency of 0.97 .

\section{RESULTS}


Clinical Psychology and Psychotherapy

Clin. Psychol. Psychother. 22, 32-44 (2015)

Published online 7 July 2013 in Wiley Online Library (wileyonlinelibrary.com). DOI: 10.1002/cpp.1862

\section{Descriptive Statistics and Preliminary Analysis}

Through the SPSS software (v. 20 SPSS, Chicago Inc., IL), we conducted the descriptive statistics presented in

Table 1. Gender differences were assessed through independente sample t-tests using SPSS (v. 20), which

showed thatmen and women did not significantly differ in age $[\mathrm{t}(159)=-0.478 ; \mathrm{p}=0.634]$ and years of education $[\mathrm{t}(125.025)=-1.583 ; \mathrm{p}=0.116]$. Therewere also no significant differences between men and women in marital status $\left(\chi_{2}=3.713 ; \mathrm{p}=0.446\right)$. Differences between men and women were also assed regarding all variables in study. There were no significant differences between men and women concerning the mean scores of early shame experiences with caregivers $[\mathrm{t}(159)=1.125 ; \mathrm{p}=0.262]$, the centrality of shame experiences with caregivers $\left[\mathrm{t}(159)=\_1.346 ; \mathrm{p}=0.180\right]$, experiential avoidance $\left[\mathrm{t}(159)=\_0.125 ; \mathrm{p}=0.902\right]$ and depression symptoms $\left[\mathrm{t}(159)=\_0.998 ; \mathrm{p}=0.320\right]$.

\section{Pearson Correlations}

Pearson correlation coefficients between all variables in the study are depicted in Table 1. As expected, the recall of early shame experiences with caregivers is positively and significantly associated with present experiential avoidance $(r=0.47 ; \mathrm{p}<0.01)$ and with the experience of depressive symptoms $(r=0.38 ; \mathrm{p}<0.01)$. Also, in accordance with our predictions, shame experiences that participants felt as being central to their life story and identity were also positively and significantly correlated with experiential avoidance $(\mathrm{r}=0.49 ; \mathrm{p}<0.01)$ and depressive symptoms $(\mathrm{r}=0.35 ; \mathrm{p}<0.01)$. The strong, positive and significant association found between experiential avoidance and depressive symptoms $(\mathrm{r}=0.67 ; \mathrm{p}<0.01)$ is also worth noticing, which is in line with our predictions and with growing literature regarding the relationship between experiential avoidance and psychopathological symptoms (e.g., Bond et al., 2011; Hayes, 2004; Iverson et al., 2011; Kumpula et al., 2011; Orcutt et al., 2005).

\section{Conceptual Mediation Model Building}

From previous literature reviews regarding early negative experiences and its relation with later experiential avoidance and psychopathological symptoms, we proposed a meditational model that includes the relations between two exogenous variables (recalled early shame experiences with caregivers and the centrality of these shaming experiences in later development of a life story and identity) and two endogenous variables (experiential avoidance and depression symptoms), one of which (experiential avoidance) acts as a mediator variable. As depicted in Figure 1, we hypothesized a cross-sectional mediation model with two indirect effects. In the first mediation, we tested the effect that experiential avoidance has on the impact of early shame experiences with caregivers that the participants felt as being central to their life story and identity on later experience of depressive symptoms. In the second mediation, we tested the effect of experiential avoidance in the relation between recall of early shame experiences with caregivers and symptoms of depression. In addition, since the relation between early shame experiences with caregivers (both the ones the participants stated as being central to their life story and identity and the ones not necessarily so-regardless of their centrality) and depression might be mediated by other processes besides experiential avoidance, two direct paths were added to the model.

\section{Analytical Plan}

We used a form of structural equation modelling called path analysis available on AMOS software (v.20, SPSS Inc.) to estimate the relations between our variables. This statistical methodology allows for the simultaneous 
examination of the direct and indirect paths when researchers have prior hypotheses about them (e.g., Schumacker \& Lomax, 2004). To estimate the hypothesized relations between the variables in study, we used path analysis with maximum likelihood estimation. Using the Mahalanobis distance statistic, data were assessed for multivariate outliers, with a chi-square cut-off of $\mathrm{p}<0.001$ as the criteria for the presence of multivariate outliers (Kline, 2005). Only two outliers were found and eliminated from our sample. Results from skewness and kurtosis coefficients showed that there was no severe violation of normal distribution ( $|\mathrm{Sk}|<3$ and $|\mathrm{Ku}|<8-10$, Kline, 2005; Kumult<10, Kline, 1998). All variables showed acceptable values of multicollinearity $(\mathrm{VIF}<5)$, assessed on SPSS. The plausibility of the overall model was assessed on the basis of several goodness-of-fit measures, such as chi-square $\left(\chi_{2}\right)$, normed chi-square $\left(\chi_{2} / \mathrm{df}\right)$, Tucker-Lewis index (TLI), comparative fit index (CFI) and the root mean square error of approximation (RMSEA) with $90 \%$ confidence interval. It is worth mentioning that in structural equation modelling, a statistically nonsignificant chi-square ( $p>0.05$ ) is desired for a fit model. According to Arbuckle's (2008) guidelines, a value of normed chi-square inferior to 5 is representative of an acceptable fit, inferior to 2 indicative of a good fit, and equal to 1 demonstrative of a perfect model fit. Additionally, Hu and Bentler's (1999) guidelines for values indicative of a good-fitting model are CFI and TLI greater than 0.95 and a RMSEA less than or equal to 0.06 . Since we included all the possible paths (direct and indirect paths between predictive and criterion variables in the two mediations in study), our initial model was a saturated model; therefore, the model fit indices were not analysed and would not be reported.

\section{Path Analysis Results}

The unstandardized regression coefficients showed that the two direct paths between recall of shame experiences $\rightarrow$ depression symptoms ( $\mathrm{t}$ statistics $=0.059 ; \mathrm{p}=0.243)$ and the centrality of the experience of shame $\rightarrow$ depression symptoms (t statistics $=0.010 ; \mathrm{p}=0.744)$ did not achieve the critical value of 1.96 for a twotailed statistical significance at the 0.05 level. More specifically, the statistical significance of each path coefficient was assessed through the comparison of the $t$ statistic (that is the critical value) with a tabled t value of 1.96 at the 0.05 level of significance. When the critical value was inferior to 1.96 , it means a path coefficient that is not significantly different from zero. Therefore, we respecified our initial ('full') model by progressively removing those two direct paths that were not statistically significant. The reduced ('trimmed') model was tested (Figure 2), and we used the chi-square difference $\left(\chi_{2} \mathrm{D}\right)$ to test the statistical significance of the decrement in overall fit with the elimination of the nonsignificant paths. Results showed that there was no difference in fit for the two models, $\chi^{2} \mathrm{D}(2, \mathrm{~N}=161)=1.60, \mathrm{p}>0.05$, hence supporting the more simplified model. The reduced model showed a very good fit, $\chi_{2}(2, \mathrm{~N}=161)=1.600, \mathrm{p}=0.449, \chi_{2} / \mathrm{df}=0.800, \mathrm{CFI}=$ $1.000, \mathrm{TLI}=1.007, \mathrm{RMSEA}=0.000 ; 90 \% \mathrm{CI}(0.000,0.147), \mathrm{p}=0.577$.

\section{Mediation Analysis}

In our final (reduced) model, all individual paths were statistically significant, as the analysis of unstandardized solutions indicated (Figure 2 presents the standardized path coefficients). The bootstrap procedure (with 2000 resamples) was used to create $95 \%$ bias-corrected confidence intervals around the standardized estimates of indirect effects, since direct paths were nonsignificant and previously removed from our model. Bootstrap is one of the most valid and powerful methods for testing mediation effects (Hayes, 2009; MacKinnon, Lockwood, \& Williams, 2004). This resampling method has been suggested to have greater capacity of detecting an indirect effect in small samples and has been pointed out as a preferable alternative to the causal 
steps approach (Preacher \& Hayes, 2008). According to this method, if zero is not between the lower and upper bounds of the $95 \%$ bias-corrected confidence interval, we can conclude that the effect is significantly different from zero ( $\mathrm{p}<0.05$, two-tailed). The occurrence of a significant standardized indirect effect but not of the standardized direct effect is the strongest demonstration of the indirect effect existence (Kline, 2005). The overall model explains $34 \%$ of experiential avoidance and $45 \%$ of depression symptoms. The shame experiences that turned out to be central to participants' life story and identity have an indirect effect on later depression symptoms, through experiential avoidance. Experiential avoidance is revealed as a strong mediator in this relationship $(\beta=0.247)$, based on bootstrap 95\% CI $(0.140,0.377), p=0.001$. We also found that the effect of recall of shame, criticismo and put-down experiences with caregivers on actual experience of depressive symptoms occurs indirectly through experiential avoidance. This indirect effect is positive $\beta=0.232$ and statistically significant [95\% CI $(0.127,0.357)], p=0.002$. In conclusion, our model suggests that shame experiences in childhood and adolescence that are felt as having a central relevance to participants' life story and identity and also the frequency and nature itself of the recalled experience (shaming, criticism and put-down experiences with caregivers) have an indirect impact on the experience of depression symptoms, through experiential avoidance.

\section{DISCUSSION}

Early shame experiences with caregivers have been widely suggested to have an impact on the development of self-relevant beliefs and self-identity (Gilbert, 1998; Kim et al., 2011; Lewis, 1992) and later psychopathology (Schore, 1998; Gilbert, 2003), particularly depression (Gilbert et al., 2003; Gilbert \& Gerlsma, 1999). In line with this and in accordance with our predictions, our results suggest that individuals whose shame experiences with others turned out to be central to their life story and identity experience more depression symptoms. However, what our results also seem to suggest is that the frequency and nature itself of shame experiences with caregivers also impact on depression symptoms. This can be explained by the impact of early shame experiences on the development of physiological systems (Schore, 1998), such as an overstimulation of defensive/threat systems that become more easily activated, giving rise to several psychopathological symptoms (Gilbert, 2003; Schore, 1998; Tangney, Burggraf, \& Wagner, 1995), such as depression (Gilbert et al., 2003; Gilbert \& Gerlsma, 1999). It has also been suggested that early adverse experiences with caregivers can have a pervasive influence on emotional self-regulatory skills (Gottman et al., 1997; Thompson \& Goodman, 2010), specifically the impact of childhood abuse on the development of experiential avoidance (Batten et al., 2001; Gratz et al., 2007; Krause et al., 2003). Given that it has been proposed that shame experiences can assume trauma-like characteristics, such as intrusion, flashbacks, emotional avoidance and hyperarousal (Gilbert, 2002; Gilbert \& Procter, 2006; Matos \& Pinto-Gouveia, 2009), we hypothesized that shame experiences with caregivers would have an impact on later experiential avoidance. In line with this and in accordance with our predictions, our results suggest that individuals whose memories of shame experiences are felt as central to their life story and identity are more likely to control their internal experiences (perhaps thoughts and emotions associated with memories of shame events). A possible explanation is that when shame experiences become central to one's life story and self-identity, these shame experiences will be seen as representative of recurrent themes in one's life story, thus serving as reference points for everyday inferences and leading to a general unwillingness to be in contact with the emotional experiences associated with those shame experiences. Since these early shame experiences with caregivers can be an anchor to everyday inferences (Berntsen \& Rubin, 2006, 2007; Pinto-Gouveia \& Matos, 2010), this 
means that a present event unrelated to those early shame experiences can elicit the same emotional experience, leading to regular attempts of controlling the form, frequency and contexto in which these emotional experiences associated with shaming memories occur. In fact, as emphasized in the ACT literature (Hayes et al., 1999), the process of eliciting the same emotional experience in a different contexto can be a consequence of language characteristics: the emotional properties of the shame experience were transferred to the present by language, resulting in an unwillingness to be in contact with those emotional properties and consequently leading to their avoidance (Blackledge \& Hayes, 2001; Hayes, 1994, 2004; Hayes et al., 1999; Wilson \& Murrell, 2003). Also in accordance to our hypothesis, it is not only those shame experiences that become central to one's life story and identity that are associated with experiential avoidance. Our results also suggest that individuals who remembre more shame, criticism and put-down experiences at the hands of their caregivers are more unwilling to experience private events (e.g., thoughts and emotions) and try to control and avoid having them. Previous studies have already shown that early negative experiences with caregivers are particularly important to the development of emotional self-regulation skills (Gottman et al., 1997; Thompson \& Goodman, 2010) and in organizing and regulating physiological systems (Schore, 1998). Since shame experiences can be easily activated through language and verbal-ruled cues (Hayes et al., 1996), individuals who recall more shame experienceswith caregivers are more likely to use emotional self-regulation processes such as experiential avoidance. We also found that individuals who tried to avoid their internal experiences presented more depression symptoms, which is in accordance with literature (Hayes, 1994; Hayes et al., 1996, 1999; Iverson et al., 2011; Santanello \& Gardner, 2007). Although experiential avoidance provides a short-term decrease on unwanted emotional experiences (Hayes et al., 1996), paradoxically, the attempts of controlling and reducing aversive internal experiences are not only futile but also counterproductive in the long term, leading to an increase of these experiences (Blackledge \& Hayes, 2001; Hayes et al., 1996), which can explain the significant association found between experiential avoidance and depression symptoms in our sample. Prior researches have suggested that experiential avoidance plays a mediating role in the relation between early negative experiences, such as abuse, and later psychopathological symptoms (Briggs \& Price, 2009; Kumpula et al., 2011; Merwin et al., 2009; Orcutt et al., 2005). Our results showed that one of the processes through which memories of shame experiences (central or not) impact on depression symptoms is experiential avoidance. This seems to suggest that it is not the memory of shame experiences (not even when those experiences are stated as central to participants' life story and identity and as anchors to daily inferences) per se that lead to depression symptoms, but the unwillingness to be in contact with unpleasant internal experiences (perhaps emotional experiences elicited by shame memories) and the attempts to control the frequency, intensity and context in which these experiences occur. In addition, it has been stated that, although experiential avoidance can lead to a short-term decrease of unpleasant internal experiences, its chronic use as a way of regulating affect is paradoxically associated with long-term detrimental effects, such as emotional disorder and dysregulation (Hayes et al., 1996, 1999). This paradoxical effect of avoidance has been empirically studied and showed that it leads to more intensity, frequency and accessibility of those experiences (Campbell-Sills et al., 2006; Wegner, Schneider, Carter, \& White, 1987). In line with this, our results suggest that, although participants who recall frequent shaming, criticism and putdown experiences with their caregivers and consider the experience of being shamed central to their life story and identity and as reference points to everyday inferences use experiential avoidance as a way of coping with their emotional experiences associated with those shame memories, its chronic use leads paradoxically to an increment of depression symptoms. In conclusion, our findings contribute to the understanding of the processes through 
which shame memories impact on depression symptoms. Our results suggest that it is not the shame memories per se that impact on depression symptoms (not even when these memories are stated as being central to one's life story and identity), but rather the unwillingness to be in contact with them and the attempt to avoid them.

\section{CLINICAL IMPLICATIONS}

This research may contribute to a better understanding of the impact of shame experiences with caregivers on depression symptomatology. Besides reinforcing existing literature on the influence of early shame experiences with caregivers on psychopathological symptoms (Gilbert, 2003; Gilbert et al., 2003; Gilbert \& Gerlsma, 1999; Schore, 1998), our research adds new information regarding the processes through which memories of shame experiences in childhood and adolescence impact on depression symptoms. More specifically, our results point out to experiential avoidance as an important psychological process through which memories of shame experiences impact on depression symptoms. We should take into consideration that our study was not conducted with a clinical sample. However, some clinical implications can be derived from it. In a therapeutic context, our results emphasizes the importance of reducing experiential avoidance, as proposed by Hayes et al. $(1996,1999)$ on ACT. Hence, an ACT intervention could be appropriate in treating depression symptoms, as has been demonstrated (Blackledge \& Hayes, 2006; Folke, Parling, \& Melin, 2012; Forman et al., 2012), since its overall goals are to decrease experiential avoidance by increasing an acceptance stance and a willingness to experience unpleasant private events, such as memories of shame. Instead of modifying the content of shame memories (which seems itself to have a pervasive impact), an ACT intervention would aim to alter the way these individuals relate with their shame memories, promoting a more accepting way of experiencing them, the contact with the presente moment and establishing a commitment with actions that are congruent with their values and life goals.

\section{LIMITATIONS OF CURRENT STUDY}

Before interpreting the results, some methodological aspects have to be taken into account. Firstly, we have to take into consideration our sample size $(\mathrm{N}=161)$. However, although it is generally understood that structural equation modelling requires large sample sizes, some factors have to be considered in order to evaluate the influence of sample size on results. According to Kline (1998), a sample size between 100 and 200 is considered a médium one, and the ratio of the number of subjects to the number of model parameters should be 10:1, which is attained in our sample ( $\mathrm{N}=161$ for 10 model parameters). In addition, since our final model is a fairly simple one (a total of 10 parameters), the estimation of statistical effects in study should not be influenced by our sample. Nevertheless, in order to draw stronger conclusions of the relation between variables, this study should be replicated with a larger sample. Furthermore, given the cross-sectional and correlational nature of the study, causal relations between variables cannot be established, only interpretations based on theoretical literature can be made. Longitudinal studies should be designed to establish the causal relations between variables studied here. In addition, participants responded to self-report questionnaires and were asked to recall early experiences; therefore, a possible selection of memories could have occurred. Perhaps a structural interview would allow a more accurate exploration of early shame experiences. However, and regarding the use of retrospective reports, it is noteworthy that it has been suggested that this type of methodology is reliable and not influenced by depressed mood (Brewin, Andrews, \& Gotlib, 1993; Richter \& Eisemann, 2001) and that the subjective interpretation of an event, rather than the event itself, is more importante to the understanding of psychopathology (Castro, 2000). Finally, since we used a general 
population sample, our results cannot be generalized to a clinical population. Future studies should replicate this research using a clinical sample in order to draw conclusions regarding the relations between the variables studied here.

\section{REFERENCES}

Andrews, B., Brewin, C.R., Rose, S., \& Kirk, M. (2000). Predicting PTSD symptoms in victims of violent crime: The role of shame, anger, and childhood abuse. Journal of Abnormal Psychology, 109, 69-73.

Andrews, B., Quian, M., \& Valentine, J.D. (2002). Predicting depressive symptoms with a new measure of shame: The experience of Shame Scale. British Journal of Clinical Psychology, 41, 29-42.

Arbuckle, J.L. (2008). AMOS 17 user's guide. Chicago, IL: SPSS Inc. Averill, P.M., Diefenbach, G.J., Stanley, M.A., Breckenridge, J.K., \& Lusby, B. (2002). Assessment of shame and guilt in a psychiatric sample: A comparison of two measures. Personality and Individual Differences, 32, 1365-1376.

Batten, S.V., Follette, V.M., \& Aban, I. (2001). Experiential avoidance and high risk sexual behavior in survivors of child sexual abuse. Journal of Child Sexual Abuse, 10(2), 101-120.

Berntsen, D., \& Rubin, D.C. (2006). The centrality of event scale: A measure of integrating a trauma into one's identity and its relation to post-traumatic stress disorder symptoms. Behaviour Research and Therapy, 44, 219-231.

Berntsen, D., \& Rubin, D.C. (2007). When a trauma becomes a key to identity: Enhanced integration of trauma memories predicts posttraumatic stress disorder symptoms. Applied Cognitive Psychology, 21, 417-431.

Berntsen, D., \& Rubin, D.C. (2008). The reappearance hypothesis revisited: Recurrent involuntary memories after traumatic events and in everyday life. Memory \& Cognition, 36, 449-460.

Berntsen, D., Rubin, D.C., \& Siegler, I.C. (2011). Two versions of life: Emotionally negative and positive life events have different roles in the organization of life story and identity. Emotion, 11, 1190-1201.

Berntsen, D., Willert, M., \& Rubin, D.C. (2003). Splintered memories or vivid landmarks? Reliving and coherence of traumatic memories in PTSD. Applied Cognitive Psychology, 17, 675-693.

Blackledge, J.T., \& Hayes, S.C. (2001). Emotion regulation in acceptance and commitment therapy. JCLP/In Session: Psychotherapy in Practice, 57(2), 243-255. Blackledge, J.T., \& Hayes, S.C. (2006). Using acceptance and commitment training in the support of parents of children diagnosed with autism. Child \& Family Behavior Therapy, 28(1), 1-18.

Bond, F.W., Hayes, S.C., Baer, R.A., Carpenter, K.C., Guenole, N., Orcutt, H.K., Waltz, T., \& Zettle, R.D. (2011). Preliminary psychometric properties of the Acceptance and Action Questionnaire-II: A revised measure of psychological flexibility and acceptance. Behavior Therapy, 42, 676-688.

Brewin, C., Andrews, B., \& Gotlib, I. (1993). Psychopathology and early experience: A reappraisal of retrospective reports. Psychological Bulletin, 113, 82-98.

Briggs, E.S., \& Price I.R. (2009). The relationship between adverse childhood experience and obsessive-compulsive symptoms and beliefs: The role of anxiety, depression and experiential avoidance. Journal of Anxiety Disorders, 23, $1037-$ 1046.

Campbell-Sills, L., Barlow, D.H., Brown, T.A., \& Hofmann, S.G. (2006). Effects of suppression and acceptance on emotional responses on individuals with anxiety and mood disorders. Behavior Research and Therapy, 44, 1251-1263.

Castilho, P., Pinto-Gouveia, J., Amaral, V., \& Duarte, J. (2012). Recall of threat and submissiveness in childhood and psychopathology: The mediator effect of self-criticism. Clinical Psychology \& Psychotherapy. DOI: 10.1002/cpp.1821

Castro, J. (2000). Perceived rearing practices and anorexia nervosa. Clinical Psychology \& Psychotherapy, 7, 320-325. Cheung, M.S.-P., Gilbert, P., \& Irons, C. (2004). An exploration of shame, social rank and rumination in relation to depression. Personality and Individual Differences, 36, 1143-1153.

Claesson, K., \& Sohlberg, S. (2002). Internalized shame and early interactions characterized by indifference, abandonment and rejection: Replicated findings. Clinical Psychology \& Psychotherapy, 9, 277-284.

Costa, J., \& Pinto-Gouveia, J. (2011). The mediation effect of experiential avoidance between coping and psychopathology in chronic pain. Clinical Psychology \& Psychotherapy, 18(1), 34-47.

Cribb, G., Moulds, M., \& Carter, S. (2006). Rumination and experiential avoidance in depression. Behaviour Change, 23(3), $165-176$.

Dinis, A., Matos, M., Pinto-Gouveia, J., \& Magalhães, C. (in preparation). Shame Experiences Scale. 
Eisenberg, N., Cumberland, A., \& Spinrad, T.L. (1998). Parental socialization of emotion. Psychological Inquiry, 9(4), 241273.

Eisenberg, N., Losoya, S., Fabes, R.A., Guthrie, I.K., Reiser, M., Murphy, B., Shepard, S.A., Poulin, R., \& Padjgett, S.J. (2001). Parental socialization of children's dysregulated expression of emotion and externalizing problems. Journal of Family Psychology, 15(2), 183-205.

Eisenberg, N., Valiente, C., Morris, A.S., Fabes, R.A., Cumberland, A.J., Reiser, M., Gershoff, E.T., Shepard, S.A., \& Losoya, S.H. (2003). Longitudinal relations among parental emotion expressivity, children regulation, and quality of socio emotional functioning. Developmental Psychology, 39(1), 3-19.

Feldner, M., Zvolensky, M., Eifert, G., \& Spira, A. (2003). Emotional avoidance: An experimental test of individual diferences and response suppression using biological challenge. Behaviour Research and Therapy, 41, 403-411.

Folke, F., Parling, T., \& Melin, L. (2012). Acceptance and Commitment Therapy for depression: A preliminary randomized clinical trial for unemployed on long-term sick leave. Cognitive and Behavioral Practice, 19, 583-694.

Forman, E.M., Shaw, J.A., Goetter, E.M., Herbert, J.D., Park, J.A., \& Yuen, E.K. (2012). Long-term follow-up of a randomized controlled trial comparing Acceptance and Commitment Therapy and standard cognitive behavior therapy for anxiety and depression. Behavior Therapy, 43, 801-811.

Gilbert, P. (1998).What is shame? Some core issues and controversies. In P. Gilbert, \& B. Andrews (eds), Shame: Interpersonal behavior, psychopathology and culture. New York, Oxford: Oxford University Press.

Gilbert, P. (2000). The relationship of shame, social anxiety and depression: The role of the evaluation of social rank. Clinical Psychology \& Psychotherapy, 7, 174-189.

Gilbert, P. (2002). Body shame: A biopsychosocial conceptualisation and overview, with treatment implications. In P. Gilbert, \& J. Miles (Eds), Body shame: Conceptualisation, research and treatment. London: Brunner-Routledge.

Gilbert, P. (2003). Evolution, social roles, and the differences in shame and guilt. Social Research, 70(4), 1205-1230.

Gilbert, P. (2005). Compassion and cruelty: A biopsychosocial approach. In P. Gilbert (Ed.), Compassion:

Conceptualisations, research and use in psychotherapy. London/New York: Routledge.

Gilbert, P., \& Gerlsma, C. (1999). Recall of shame and favouritism in relation to psychopathology. The British Journal of Clinical Psychology, 38, 357-373.

Gilbert, P., \& Irons, C. (2005). Focused therapies and compassionate mind training for shame and self-attacking. In P. Gilbert (Ed.), Compassion: Conceptualisations, research and use in psychotherapy (pp. 235-263). London/New York: Routledge.

Gilbert, P., \& McGuire, M. (1998). Shame, status and social roles: Psychobiology and evolution. In P. Gilbert \& B. Andrews (Eds), Shame: Interpersonal behavior, psychopathology and culture. New York, Oxford: Oxford University Press.

Gilbert, P., \& Procter, S. (2006) Compassion mind training for people with high shame and self-criticism: Overview and pilot study of a group therapy approach. Clinical Psychology \& Psychotherapy, 13, 353-379.

Gilbert, P., Allan, S., \& Goss, K. (1996). Parental representations, shame, interpersonal problems, and vulnerability to psychopathology. Clinical Psychology And Psychotherapy, 3(1), 23-24.

Gilbert, P., Cheung, M., Grandfield, T., Campey, F., \& Irons, C. (2003) Recall of threat and submissiveness in childhood: Development of a new scale and its relationship with depression, social comparison and shame. Clinical Psychology \& Psychotherapy, 10, 108-115.

Gilbert, P., McEwan, K., Mitra, R., Franks, L., Richter, A., \& Rockliff, H. (2008). Feeling safe and content: A specific affect regulation system? Relationship to depression, anxiety, stress, and self-criticism. Journal of Positive Psychology, 3, 182191.

Goss, K., \& Allan, S. (2009). Shame, pride and eating disorders. Clinical Psychology \& Psychotherapy, 16, 303-316. Gottman, J.M., Katz, L.F., \& Hooven, C. (1997). Meta-emotion. How families communicate emotionally. Mahwah, NJ: Erlbaum.

Grabhorn, R., Stenner, H., Stangier, U., \& Kaufhold, J. (2006). Social anxiety in anorexia and bulimia nervosa: The mediating role of shame. Clinical Psychology \& Psychotherapy, 13, 12-19.

Gratz, K.L., Bornovalova, M.A., Delany-Brumsey, A., Nick, B., \& Lejuez, C.W. (2007). A laboratory-based study of the relationship between childhood abuse and experiential avoidance among inner-city substance users: The role of emotional nonacceptance. Behavior Therapy, 38(3), 256-268.

Greenberg, D.L., \& Rubin, D.C. (2003). The neuropsychology of autobiographical memory. Cortex, 39, 687-728. 
Gross, J.J. (1998). Antecedent- and response-focused emotion regulation. Journal of Personality and Social Psychology, 74(1), 224-237.

Habermas, T., \& Bluck, S. (2000). Getting a life: The emergence of the life story in adolescence. Psychological Bulletin, $126,748-769$

Halberstadt, A.G. (1986). Family socialization of emotional expression and nonverbal communication styles and skills. Journal of Personality and Social Psychology, 51 (4), 827-836.

Hayes, S.C. (1994). Content, context, and the types of psychological acceptance. In S.C. Hayes, N.S. Jacobson, V.M. Follette, \& M.J. Dougher (Eds.), Acceptance and change: Content and contexto in psychotherapy (pp. 13-32). Reno, NV: Context Press.

Hayes, S.C. (2004). Acceptance and commitment therapy and the new behavior therapies: Mindfulness acceptance and relationship. In S.C. Hayes, V.M. Follete, \& M.M. Linehan (Eds.), Mindfulness and acceptance: Expanding the cognitivebehavioral tradition (pp. 1-26). New York: Guilford Press.

Hayes, A.F. (2009). Beyond Baron and Kenny: Statistical mediation analysis in the new millennium. Communication Monographs, 76, 408-420.

Hayes, S.C., Strosahl, K., \& Wilson, K.G. (1999). Acceptance and commitment therapy: An experiential approach to behavior change. New York: Guilford Press.

Hayes, S.C., Wilson, K.G., Gifford, E.V., Follette, V.M., \& Strosahl, K. (1996). Experiential avoidance and behavioral disorders: A functional dimensional approach to diagnosis and treatment. Journal of Consulting and Clinical Psychology, $64,1152-1168$

Holland, A.C., \& Kensinger, E.A. (2010). Emotion and autobiographical memory. Physics of Life Reviews, 7, 88-131. Hu, L.T., \& Bentler, P.M. (1999). Cutoff criteria for fit indexes in covariance structure analysis: Conventional criteria versus new alternatives. Structural Equation Modeling, 6 (1), 1-55.

Irons, C., Gilbert, P., Baldwin, M.W., Baccus, J.R., \& Palmer, M. (2006). Parental recall, attachment relating and selfattacking/self-reassurance: Their relationship with depression. British Journal of Clinical Psychology, 45, 297-308.

Iverson, K.M., Follette, V.M., Pistorello, J., \& Fruzzetti, A.E. (2011). An investigation of experiential avoidance, emotion dysregulation, and distress tolerance in young adult outpatients with borderline personality disorder symptoms. Personality Disorders: Theory, Research, and Treatment, 3(4), 415-422.

Kashdan, T.B., Barrios, V., Forsyth, J.P., \& Steger, M.F. (2006). Experimental avoidance as a generalized psychological vulnerability: Comparisons with coping and emotion regulation strategies. Behaviour Research and Therapy, 9, 1301-1320.

Kaufman, J. (1989). The psychology of shame: Theory and treatment of shame-based syndromes. (2nd ed.). New York: Springer Publishing Company.

Keith, L., Gillanders, D., \& Simpson, S. (2009). An exploration of the main sources of shame in an eating disordered population. Clinical Psychology \& Psychotherapy, 16, 317-327.

Kim, S., Thibodeau, R., \& Jorgensen, R.S. (2011). Shame, guilt, and depressive symptoms: A meta-analytic review. Psychological Bulletin, 137(1), 68-96.

Kline, R.B. (1998). Principles and practice of structural equation modeling. New York: Guilford Press.

Kline, R.B. (2005). Principles and practice of structural equation modeling (2nd ed.). New York: Guilford.

Krause, E.D., Mendelson, T., \& Lynch, T.R. (2003). Childhood emotional invalidation and adult psychological distress: The mediating role of emotional inhibition. Child Abuse \& Neglect, 27, 199-213.

Kumpula, M.J., Orcutt, H.K., Bardeen, J.R., \& Varkovitzky, R.L. (2011). Peritraumatic dissociation and experiential avoidance as prospective predictors of posttraumatic stress symptoms. Journal of Abnormal Psychology, 120(3): 617-627

Lewis, M. (1992). The socialization of shame: From parent to child. In M. Lewis (Ed.), Shame: The exposed self. New York: Free Press.

Lovibond, P.F., \& Lovibond, S.H. (1995). The structure of negative emotional states: Comparison of the Depression Anxiety Stress Scales (DASS) with the Beck Depression and Anxiety Inventories. Behaviour Research and Therapy, 33(3), $335-343$.

MacKinnon D.P., Lockwood C.M., \& Williams J. (2004). Confidence limits for the indirect effect: Distribution of the product and resampling methods. Multivariate Behavioral Research, 39, 99-128. 
Clinical Psychology and Psychotherapy

Clin. Psychol. Psychother. 22, 32-44 (2015)

Published online 7 July 2013 in Wiley Online Library (wileyonlinelibrary.com). DOI: 10.1002/cpp.1862

Matos, M., \& Pinto-Gouveia, J. (2009). Shame as a traumatic memory. Clinical Psychology \& Psychotherapy, 17(4), 299 312 .

Matos, M., Pinto-Gouveia, J., \& Costa, V. (2011). Understanding the importance of attachment in shame traumatic memory relation to depression: The impact of emotion regulation processes. Clinical Psychology \& Psychotherapy. DOI: 10.1002/ cpp.786

Matos, M., Pinto-Gouveia, J., \& Gomes, P. (2010). A centralidade das experiências da vergonha: Estudos das propriedades psicométricas da versão portuguesa da Escala da Centralidade do Acontecimento. Psicologia, 24(1), 74-95.

Merwin, R.M., Rosenthal, M.Z., \& Coffey, K.A. (2009). Experiential avoidance mediates the relationship between sexual victimization and psychological symptoms: Replicating findings with an ethnically diverse sample. Cognitive Therapy and Research, 33(5), 537-542.

Mikulincer, M., \& Shaver, P.R. (2005). Mental representations of attachment security: Theoretical foundation for a positive social psychology. In M.W. Baldwin (Ed.), Interpersonal cognition (pp. 233-266). New York: Guilford Press.

Mills, R.S.L. (2005). Taking stock of the developmental literature on shame. Developmental Review, 25, 26-63.

Mills, R.S.L., Arbeau, K.A., Lall, D.I.K., \& De Jaeger, A.E. (2010). Parenting and child characteristics in the prediction of shame in early and middle childhood. Merrill-Palmer Quarterly, 56, 500-528.

Nolen-Hoeksema, S., \& Harrel, Z.A. (2002). Rumination, depression, and alcohol use: Tests of gender differences. Journal of Cognitive Psychotherapy: An International Quarterly, 16(4), 391-403.

Orcutt, H.K., Pickett, S., \& Pope, E. (2005). Experiential avoidance and forgiveness as mediators in the relation between traumatic life events and PTSD symptoms. Journal of Social and Clinical Psychology, 24, 1003-1029.

Pais-Ribeiro, J., Honrado, A., \& Leal, I. (2004). Contribuição para o estudo da adaptação portuguesa das escalas de Depressão Ansiedade e Stress de Lovibond e Lovibond. Psycologica, 36, 235-246.

Parker, G., Tupling, H., \& Brown, L. (1979). A parental bonding instrument. The British Journal of Medical Psychology, $52,1-10$.

Pinto-Gouveia, J., \& Matos, M. (2010). Can shame memories become a key to identity? The centrality of shame memories predicts psychopathology. Applied Cognitive Psychology. DOI:10.1002/acp.1689

Pinto-Gouveia, J., Gregório, S., Dinis, A., \& Xavier, A. (2012). Experiential avoidance in clinical and nonclinical samples. International Journal of Psychology and Psychological Therapy, 12 (2), 139-156.

Porter, S., \& Peace, K. (2007). The scars of memory: A prospective, longitudinal investigation of the consistency of traumatic and positive emotional memories in adulthood. Psychological Science, 18, 435-441.

Preacher, K.J., \& Hayes, A.F. (2008). asymptotic and resampling strategies for assessing and comparing indirect effects in multiple mediator models. Behavior Research Methods, 40(3), 879-871.

Richter, J., \& Eisemann, M. (2001). Stability of memories of parental rearing among psychiatric inpatients: A replication based on EMBU subscales. Psychopathology, 34(6), 318-325.

Robinaugh, D.J., \& McNally, R.J. (2010). Autobiographical memory for shame or guilt events: Association with psychological symptoms. Behaviour Research and Therapy, 48, 646-652.

Rubin, D.C., \& Berntsen, D. (2009). The frequency of voluntary and involuntary autobiographical memories across the lifespan. Memory \& Cognition, 37, 679-688.

Rubin, D.C., Dennis, M.F., \& Beckham J.C. (2011). Autobiographical memory for stressful events: The role of autobiographical memory in posttraumatic stress disorder. Consciousness and Cognition, 20, 840-856.

Santanello, A.W., \& Gardner, F.L. (2007). The role of experiential avoidance in the relationship between maladaptive perfectionism and worry. Cognitive Therapy and Research, 31(3), 319-332.

Schore, A.N. (1998) Early shame experiences and infant brain development. In P. Gilbert, \& B. Andrews (Eds.), Shame: Interpersonal behavior: Psychopathology and culture. New York: Oxford University Press.

Schumacker, R.E., \& Lomax, R.G. (2004). A beginner's guide to structural equation modeling (2nd ed.). Mahwah, NJ: Lawrence Erlbaum Associates, Inc..

Smith, N., Lam, D., Bifulco, A., \& Checkley, S. (2002). Childhood Experience of Care and Abuse Questionnaire (CECA.Q). Validation of a screening instrument for childhood adversity in clinical populations. Social Psychiatry and Psychiatric Epidemiology, 37, 572-579. 
Sutherland, K., \& Bryant, R.A. (2008). Social problem solving and autobiographical memory in posttraumatic stress disorder. Behaviour Research and Therapy, 46, 154-161.

Talarico, J.M., LaBar K.S., \& Rubin, D.C. (2004). Emotional intensity predicts autobiographical memory experience. Memory \& Cognition, 32, 1118-1132.

Tangney, J.P., \& Dearing, R. (2002). Shame and guilt. New York: Guilford.

Tangney, J., Burggraf, S., \& Wagner, P. (1995). Shame-proneness, guilt-proneness, and psychological symptoms. In J. Tangney \& K. Fischer (Eds.), Self-conscious emotions: The psychology of shame, guilt, embarrassment, and pride (pp. 343367) New York: Guilford

Tangney, J., Wagner, P., \& Gramzow, R. (1992). Proneness to shame, proneness to guilt and psychopathology. Journal of Abnormal Psychology, 101(3), 469-478.

Thompson, R.A., \& Goodman, M. (2010). Development of emotion regulation: More than meets the eye. In A.M. Kring \& D. M. Sloan (Eds.), Emotional regulation and psychopathology: A transdiagnostic approach to etiology and treatment (pp. 38-58). New York: The Guilford Press.

Thomsen D.K., \& Berntsen D. (2009). The long-term impact of emotionally stressful events on memory characteristics and life story. Applied Cognitive Psychology, 23(4), 579-598.

Valiente, C., Fabes, R.A., Eisenberg, N., \& Spinrad, T.L. (2004). The relations of parental expressivity and support to children's coping with daily stress. Journal of Family Psychology, 18(1), 97-106.

Wegner, D.M., Schneider, D.J., Carter, S., \& White, T. (1987). Paradoxical effects of thought suppression. Journal of Personality and Social Psychology, 53, 5-13.

Wekerle, C., Leung, E., Wall, A.M., MacMillan, H., Boyle, M., Trocmé, N., \& Waechter, R. (2009). The contribution of childhood emotional abuse to teen dating violence among child protective services-involved youth. Child Abuse \& Neglect, 33 (1), 45-58

Wenzel, A., Pinna, K., \& Rubin, D.C. (2004). Autobiographical memories of anxiety-related experiences. Behaviour Research and Therapy, 42, 329-341.

Wilson, K.G., \& Murrell, A.R. (2003). Values-centered interventions: Setting a course for behavioral treatment. In S.C. Hayes, V.M. Follette, \& M. Linehan (Eds.), The new behavior therapies: Expanding the cognitive behavioral tradition. New York: Guilford Press.

Table 1. Means, standard deviations, range of scores and correlations between all measured variables $(\mathrm{N}=161)$

\begin{tabular}{lcccccc}
\hline & M & SD & Min-max & SES & CES & AAQ-II \\
SES & 1.70 & 0.59 & $1.00-4.07$ & - & - & - \\
CES & 2.08 & 0.93 & $1.00-4.95$ & $0.34^{* *}$ & - & - \\
AAQ-II & 18.41 & 8.12 & $1.00-6.43$ & $0.47^{* *}$ & $0.49^{* *}$ & - \\
Depression DASS & 5.53 & 6.18 & $0.00-2.36$ & $0.38^{* *}$ & $0.35^{* *}$ & $0.67^{* *}$ \\
\hline
\end{tabular}

SES = Shame Experiences Scale. CES = Centrality of Event Scale. AAQ-II = Acceptance and Action Questionnaire. DASS =Depression Anxiety Stress

Scale.

$* * \mathrm{p}<0.01$. 
Clinical Psychology and Psychotherapy

Clin. Psychol. Psychother. 22, 32-44 (2015)

Published online 7 July 2013 in Wiley Online Library (wileyonlinelibrary.com). DOI: 10.1002/cpp.1862

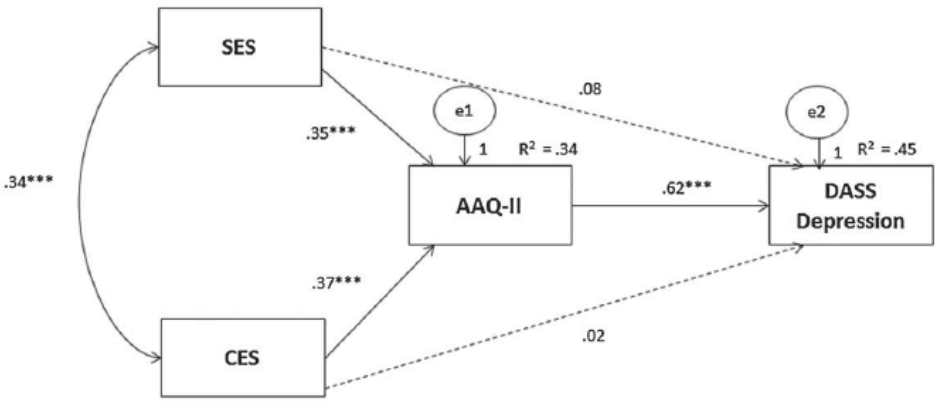

Note. Standardized path coefficients among variables are presented.

$* * * p<.001$.

Path SES $\rightarrow$ DASS Depression and path CES $\rightarrow$ DASS Depression are non-significant at the .05 level. $S E S=$ shame experiences scale $; C E S=$ centrality of event scale; $A A Q=$ acceptance and action questionnaire; $D A S S=$ depression anxiety stress scale.

Figure 1. Initial (saturated) model 
Published online 7 July 2013 in Wiley Online Library (wileyonlinelibrary.com). DOI: 10.1002/cpp.1862

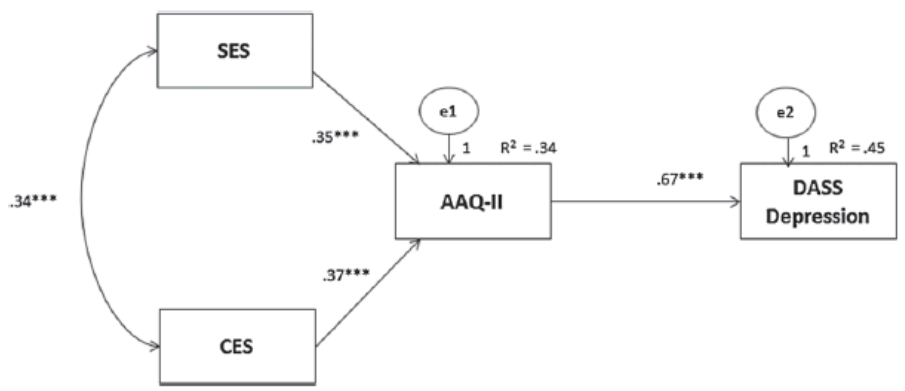

Note. Standardized path coefficients among variables are presented. All path coefficients are significant at the .05 level. $\chi^{2}(2, N=161)=1.600, p=.449, \chi^{2} / d . f .=.800, C F I=1.000, T L I=1.007, R M S E A=.0 .000$ $(C I=.000 ; .147), p=.577$.

SES $=$ shame experiences scale $; C E S=$ centrality of event scale; $A A Q=$ acceptance and action questionnaire; DASS $=$ depression anxiety stress scale.

$* * * p<.001$.

Figure 2. Final (reduced) meditational model 